\title{
Safe and Quantitative Analysis of Nuclear Materials From the Milli to Nano-Scale
}

\author{
Robert Ulfig $^{1}$, David Reinhard ${ }^{1}$, Anne-Sophie Robbes ${ }^{2}$, Paula Peres ${ }^{2}$ and David Larson ${ }^{1}$ \\ ${ }^{1}$ CAMECA Instruments Inc., Madison, Wisconsin, United States, ${ }^{2}$ CAMECA, Gennevilliers, France
}

Nuclear fission supplies about one-third of the world's carbon-free electricity and is expected to grow by $50 \%$ in the next ten years, primarily through heavy expansion in Asia [1]. Nanoscale research on nuclear materials has accelerated to meet the materials challenges of these new reactors as well as lifetime extensions of fission power plants. In addition, the research into accident-resistant fuel in the wake of the Fukushima meltdown, and the now very real-world new materials problems surrounding the construction and operation of megawatt neutron-rich 100 million-degree fusion reactors [2], provide ample new materials challenges.

Nuclear materials research encompasses a wide range of structural, protective, damage resistant, and fuel materials including metals, insulators, and composites. These materials may be non-irradiated, irradiated, but not radioactive, or radioactive with specific activities ranging from the activity of a banana to deadly outputs of ionizing radiation. Quantitative micro and nanoscale post irradiation examination (PIE) often requires highly modified sample handling and preparation to protect the microscopist. It can also require substantially modified microscopes to meet both regulatory personal protection requirements and to protect the proper operation of the instrument. The tried-and-true focus on time, distance, and shielding, as well as contamination control, needs to be considered in every step of the analysis procedure.

CAMECA $^{\circledR}$ offers nuclearized versions of instruments from their electron probe microanalysis (EPMA), atom probe tomography (APT), and secondary ionization mass spectrometer (SIMS) product lines enabling quantitative analysis from the millimeter to nanometer spatial range and from the percent to parts-per-trillion detection range. These instruments include custom specimen handling, contamination control, and personal protection modifications as well as key design changes to minimize the risk of damage or the introduction of errant noise to the detection systems during PIE.

EPMA is a non-destructive, qualitative, and quantitative method of elemental analysis of micron-sized volumes near the surface of materials, with sensitivity at the level of hundreds of ppm. SKAPHIA ${ }^{\circledR}$, Fig. 1a, is CAMECA's latest generation shielded EPMA, providing a safe environment for manipulating and analyzing radioactive materials. It is designed to accept samples emitting beta and gamma radiation up to $50 \mathrm{~Gy} / \mathrm{hr}$. All wavelength dispersive spectrometers and electron detectors are shielded to prevent the background caused by the radiation and the stage is made of a tungsten composite material to reduce background noise to enhance detection sensitivity. The electronics and computer controls are located remotely for convenient and safe analysis.

The CAMECA ACTINIS ${ }^{\circledR}$, Fig. 1b, is a magnetic sector SIMS instrument based on the CAMECA IMS $7 \mathrm{f}-\mathrm{Geo}$ configuration and is specifically designed for highly radioactive samples. Offering high mass resolution and high transmission, it delivers high-sensitivity depth profiling and isotope ratio measurements as well as element and isotope mapping at sub-micron lateral resolution, Fig $2 \mathrm{~b}$.

The shielding package includes a glove box with a manipulator for alpha protection and lead shielding surrounding the glove box, the entry airlock, and the specimen chamber. A leaded glass window permits visualization of sample manipulation and performance of maintenance operations. After installation of the 
biological protections, the maximum activity of the sample that can be analyzed in the SIMS instrument is $2 \mathrm{~Gy} / \mathrm{h}$ measured at $5 \mathrm{~cm}$ from the sample. The equivalent dose outside the biological protections is less than $25 \mu \mathrm{Sv} / \mathrm{h}$.

The LEAP ${ }^{\circledR} 5000$ APT instrument has a configuration that is optimized for the analysis of radioactive materials. It includes a physical containment vessel to move specimens from preparation and treatment systems to the LEAP safely and under controlled environmental conditions Fig. 1c, an in-vacuum collection tray for the collection of specimen debris, a high-density flight path shield, and optic to protect the detector from radiation, as well as extended puck handling tools and remote vertical transfer controls for enhanced operator safety. Using the commercially available microtip array carriers, greater than 20 specimens can be loaded into the LEAP and analyzed remotely.

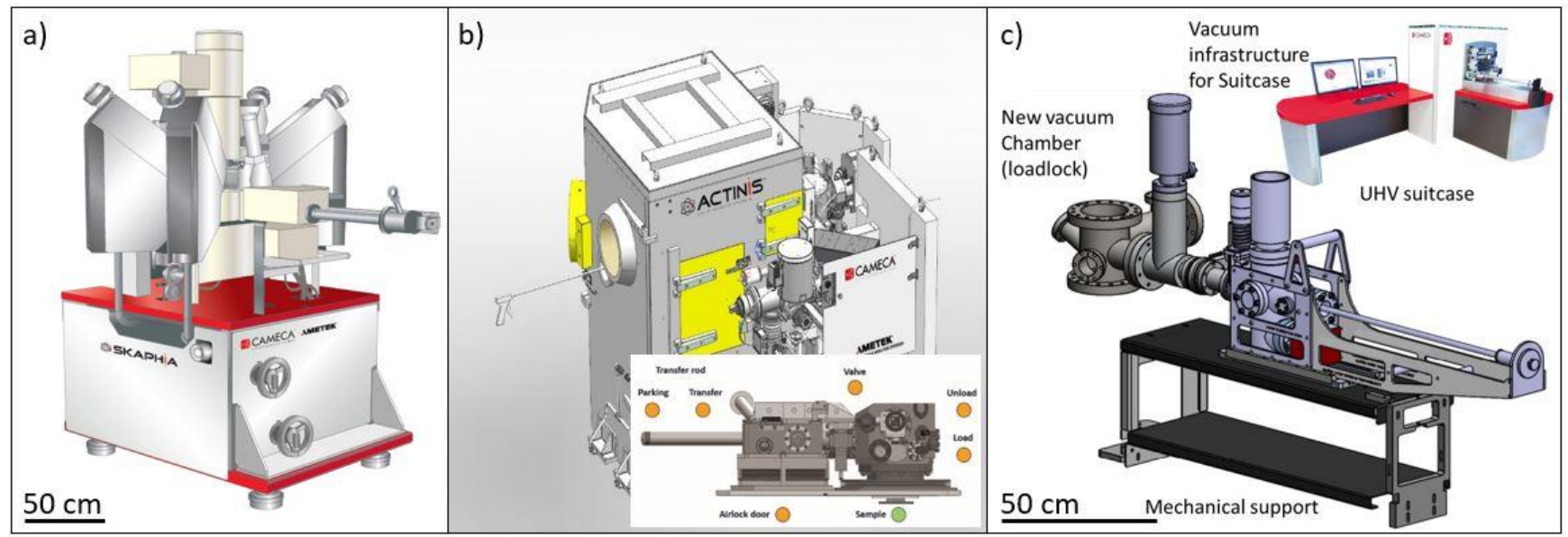

Figure 1. CAMECA's nuclearized product line includes (a) the SKAPHIA, (b) the ACTINIS, and (c) the nuclearization of the LEAP, including the innert/cryo/vacuum capable radiation/contamination transfer module.

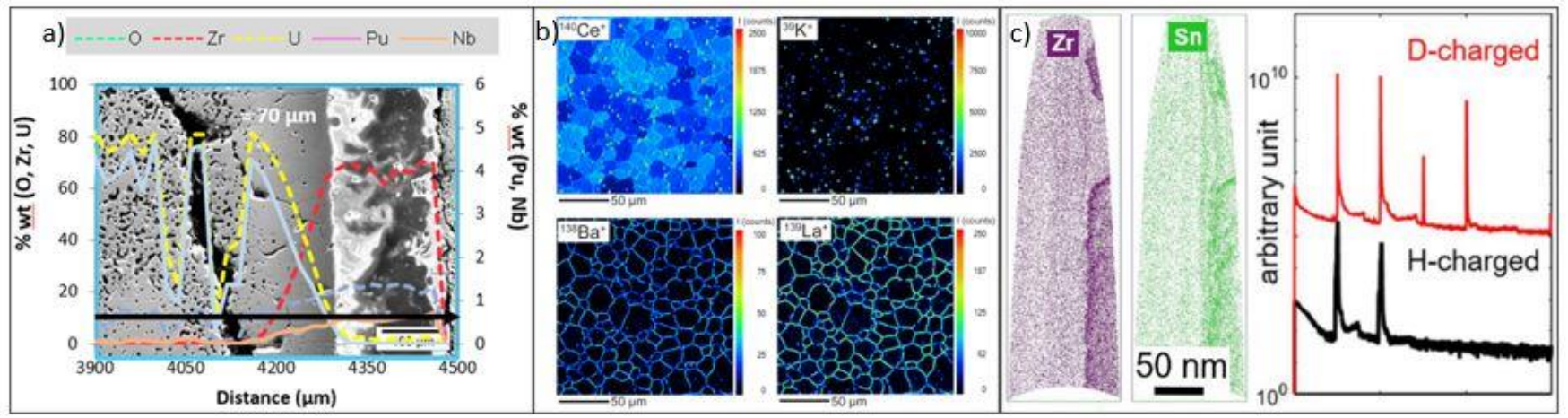

Figure 2. (a) Interdiffusion of $\mathrm{U}$ and $\mathrm{Zr}$ takes place at the interface between the fuel and the cladding. Quantitative profiles produced in this area reveal an interdiffusion distance over approximately $70 \mu \mathrm{m}$ [3]. (b) SIMS imaging data obtained in Xe implanted $\mathrm{CeO} 2$ sample for $\mathrm{Ce}$ matrix species and $\mathrm{K}$, $\mathrm{Ba}, \mathrm{La}$ contaminants [4]. (c) Distribution of species for $\mathrm{Zr}, \mathrm{Sn}, 1 \mathrm{H}$, and $2 \mathrm{H}$ (D) in zircalloy fuel cladding at the deuteride/ $\alpha-\mathrm{Zr}$ interface. Sections of the mass spectrum in the range of 1-6 Da and Da obtained for the hydride (black) and the deuteride (red) [5].

\section{References}


[1] IAEA Power Reactor Information Service, https://pris.iaea.org/ (2/7/2021).

[2] B. Bigot, Nuclear News, January (2021) 34.

[3] Le Gall et al., Journal of Nuclear Materials 531 (2020) 152015.

[4] P. Peres et al., JVST B 36, (2018) 03F117-1.

[5] I. Mouton, et al., Microsc and Micro 25, (2019) 481. 